\title{
Computed tomography features of resected lung adenocarcinomas with spread through air spaces
}

Gouji Toyokawa, PhD, ${ }^{\mathrm{a}}$ Yuichi Yamada, $\mathrm{PhD},{ }^{\mathrm{b}}$ Tetsuzo Tagawa, $\mathrm{PhD},{ }^{\mathrm{a}}$ Takeshi Kamitani, MD, Yuzo Yamasaki, $\mathrm{PhD},{ }^{\mathrm{c}}$ Mototsugu Shimokawa, $\mathrm{PhD},{ }^{\mathrm{d}}$ Yoshinao Oda, $\mathrm{PhD},{ }^{\mathrm{b}}$ and Yoshihiko Maehara, $\mathrm{PhD}^{\mathrm{a}}$

\section{ABSTRACT}

Background: Spread through air spaces (STAS) is a recently recognized invasive pattern of lung cancer defined as "micropapillary clusters, solid nests, or single cells beyond the edge of the tumor into air spaces." Since STAS has been shown to be a significant prognosticator for the postoperative survival, predicting STAS preoperatively by computed tomography (CT) might help determine the optimum surgical procedures.

Methods: Information on STAS and preoperative CT was available in 327 patients with resected lung adenocarcinomas. STAS was defined as tumor cells within air spaces in the lung parenchyma beyond the edge of the main tumor. The association of STAS with CT characteristics, such as vascular convergence, ground-glass opacity (GGO), air bronchogram, notch, pleural indentation, spiculation, and cavitation, was analyzed.

Results: Among the 327 patients with resected adenocarcinoma, 191 (58.4\%) were positive for STAS. A univariable analysis demonstrated that STASpositive adenocarcinomas were significantly associated with a larger radiologic tumor diameter $(P=.02)$, the presence of vascular convergence $(P<.01)$, notch $(P<.01)$, pleural indentation $(P=.03)$, spiculation $(P<.01)$, and the absence of GGO $(P<.01)$ compared with STAS-negative ones. In a multivariable analysis, the presence of notch $(P=.01)$ and the absence of GGO $(P<.01)$ were shown to be significantly associated with the STAS phenomenon. The odds ratio for STAS of notch-positive and GGO-negative adenocarcinomas against notchnegative and GGO-positive ones was $5.01(P<.01)$.

Conclusions: The presence of notch and the absence of GGO were independently associated with the STAS phenomenon. These results will prove helpful in identifying STAS-positive adenocarcinoma by CT before surgical resection. (J Thorac Cardiovasc Surg 2018;156:1670-6)

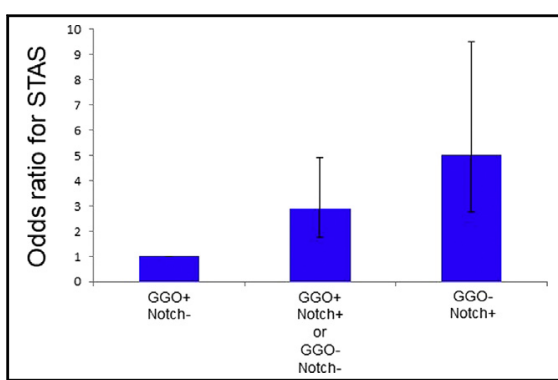

Odds ratio for STAS according to the presence or absence of GGO and notch.

\section{Central Message}

The presence of notch and the absence of GGO were independently associated with the STAS phenomenon in resected lung adenocarcinomas.

\section{Perspective}

We analyzed the association of STAS with CT characteristics, such as vascular convergence, GGO, air bronchogram, notch, pleural indentation, spiculation, and cavitation, in resected lung adenocarcinomas. The presence of notch and the absence of GGO were independently associated with STAS. These results will prove helpful in identifying STAS-positive adenocarcinoma by $\mathrm{CT}$ before surgical resection.

See Editorial Commentary page 1677

See Editorial page 1667
Spread through air spaces (STAS) was first introduced by Kadota and colleagues in $2015,{ }^{1}$ and its conception in lung adenocarcinoma was newly described in the 2015 World Health Organization (WHO) classification. STAS has attracted much attention, as it might be a novel invasive pattern that is separate from the existing invasive patterns

From the Departments of ${ }^{\mathrm{a}}$ Surgery and Science, ${ }^{\mathrm{b}}$ Anatomic Pathology, and ${ }^{\mathrm{c}}$ Clinical Radiology, Graduate School of Medical Sciences, Kyushu University, Fukuoka; and ${ }^{\mathrm{d} C l i n i c a l}$ Research Institute, National Kyushu Cancer Center, Fukuoka, Japan.

Received for publication Jan 26, 2018; revisions received April 24, 2018; accepted for publication April 28, 2018; available ahead of print June 28, 2018.

Address for reprints: Gouji Toyokawa, PhD, Department of Surgery and Science, Graduate School of Medical Sciences, Kyushu University, 3-1-1 Maidashi, Higashi-ku, Fukuoka 812-8582, Japan (E-mail: gouji104kawa@gmail.com). $0022-5223 / \$ 36.00$

Copyright (c) 2018 by The American Association for Thoracic Surgery

https://doi.org/10.1016/j.jtcvs.2018.04.126 (ie, a histologic subtype other than a lepidic pattern; myofibroblastic stroma associated with invasive tumor cells; and vascular or pleural invasion). The 2015 WHO classification defines STAS as follows: "micropapillary clusters, solid nests, or single cells spreading within air spaces beyond the edge of the main tumor"; however, the definition of STAS varies among studies. ${ }^{2}$

With regard to the clinicopathologic features of lung adenocarcinoma with the STAS phenomenon, several studies

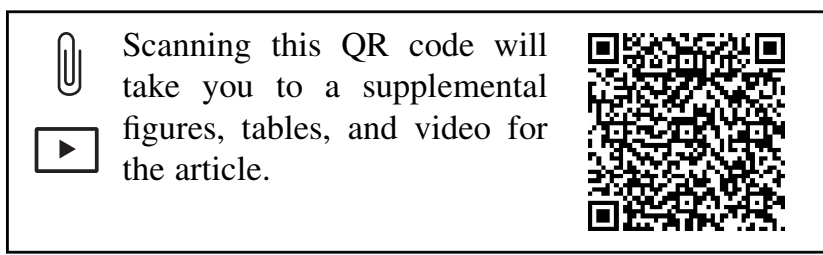




$$
\begin{aligned}
& \text { Abbreviations and Acronyms } \\
& \begin{aligned}
\mathrm{CI} & =\text { confidence interval } \\
\mathrm{CT} & =\text { computed tomography } \\
\mathrm{C} / \mathrm{T} & =\text { consolidation/tumor } \\
E G F R & =\text { epidermal growth factor receptor } \\
\mathrm{GGO} & =\text { ground-glass opacity } \\
\mathrm{OR} & =\text { odds ratio } \\
\mathrm{OS} & =\text { overall survival } \\
\mathrm{PD}-\mathrm{L} 1 & =\text { programmed cell death-ligand } 1 \\
\mathrm{PY} & =\text { pack-years } \\
\text { RFS } & =\text { recurrence-free survival } \\
\text { STAS } & =\text { spread through air spaces } \\
\text { WHO } & =\text { World Health Organization }
\end{aligned}
\end{aligned}
$$

have demonstrated the association of STAS with male sex, a smoking history, greater carcinoembryonic antigen levels, solid components on computed tomography (CT), lymph node metastasis, advanced pathologic stage, and lymphovascular and pleural invasion. ${ }^{1,3-6}$ Furthermore, mutations in the Kirsten rat sarcoma viral oncogene homolog (ie, KRAS) and $v$-Raf murine sarcoma viral oncogene homolog $B$ (ie, BRAF) genes were reported to be significantly associated with STAS, ${ }^{3}$ whereas STAS was more frequently observed in wildtype epidermal growth factor receptor $(E G F R)$ than in mutated $E G F R .{ }^{4}$ Regarding the association between STAS and the programmed death-ligand 1 (PD-L1) expression, a key element in the tumor microenvironment, our unpublished data showed no significant association between these factors (data not shown).

The prognostic impact of STAS has been widely investigated, and several studies have demonstrated the negative impact of STAS on the postoperative survival in both lung adenocarcinoma and squamous cell carcinoma. ${ }^{1,4,5,7,8}$ Among these reports, Kadota and colleagues ${ }^{1}$ reported that STAS was significantly associated with recurrence in early-stage adenocarcinomas after limited resection, not lobectomy, suggesting that such small adenocarcinomas should be treated with lobectomy combined with systematic dissection of lymph nodes, not limited resection. As such, being able to predict STAS by CT or other modalities before surgical resection would aid in the selection of the optimum surgical procedure. However, there are no reports describing the relationship between the STAS phenomenon and $\mathrm{CT}$ features, such as vascular convergence, surrounding ground-glass opacity (GGO), air bronchogram, notch, pleural indentation, spiculation, and cavity formation.

The objectives of our study were to investigate how well CT features can predict or discriminate STAS status before surgery and, ultimately, whether they could help to direct appropriate surgical decision-making. We investigated the relationship between CT characteristics and the STAS phenomenon in 327 patients with resected lung adenocarcinoma.

\section{PATIENTS AND METHODS \\ Patients}

We retrospectively examined patients who underwent surgical resection of primary lung adenocarcinoma between January 2003 and December 2012 at the Department of Surgery and Science, Graduate School of Medical Sciences, Kyushu University. Four hundred seventeen paraffin-embedded specimens were retrieved from the registry of the Department of Anatomic Pathology, Graduate School of Medical Sciences, Kyushu University. Among these 417 patients, the pathologic slides of 7 patients were not available for the assessment of STAS, and 83 patients were excluded from this study because CT was not performed before the surgery or was performed at another hospital. Therefore, of the 417 subjects, only 327 were ultimately included in this study. The clinicopathologic features, including the age at surgery, sex, smoking history, pathologic tumor-node-metastasis stage (seventh edition of the lung cancer staging system), histologic subtype (WHO classification 2015), and EGFR mutation status, were examined. The smoking status was divided into 3 groups based on the history of smoking (in packyears $[\mathrm{PY}])$ : never smoker $(\mathrm{PY}=0)$, light smoker $(\mathrm{PY} \leq 30)$, and heavy smoker $(\mathrm{PY}>30)$. The EGFR status was determined in tumor tissue using the peptide nucleic acid-locked nucleic acid polymerase chain reaction clamp method (Mitsubishi Chemical Medience, Tokyo, Japan) in 204 specimens. ${ }^{9}$ Immunohistochemistry for the PD-L1 expression was performed using an anti-human PD-L1 rabbit monoclonal antibody (clone SP142, dilution 1:100; Spring Bioscience, Ventana, Tucson, Ariz) and evaluated as described previously. ${ }^{10}$ In brief, systemic dissection of the hilar and mediastinal lymph nodes was performed at the same time as pulmonary lobectomy. Perioperative therapy was performed in compliance with the clinical practice guidelines for lung cancer in Japan. After surgery, routine checkups, including a physical examination, blood tests, and chest radiograph, were performed at 3-month intervals for the first 3 years and at 6-month intervals thereafter. CT was performed twice a year for the first 3 years and then at least annually thereafter. Clinical information and follow-up data were obtained from the medical records. This study was approved by our institutional review board (approval number: 29-322).

\section{Spread Through Air Spaces}

STAS was defined as tumor cells within air spaces in the lung parenchyma beyond the edge of the main tumor. ${ }^{3,4}$ The pathologist ruled out single tumor cells/clusters with broken figures as artifacts because the finding suggests unnaturally separated cells/clusters. All tumors were evaluated at a magnification of $\times 200$ with an optical microscope (BX40; Olympus, Tokyo, Japan).

\section{Chest CT}

In general, patients underwent chest $\mathrm{CT}$ within 1 month before surgery. Chest CT was performed with the patient in the supine position during inspiratory breath-hold using various multidetector row scanners: Aquilion 4 (TOSHIBA Corporation, Tokyo, Japan), Aquilion 64 (TOSHIBA), Aquilion ONE (TOSHIBA), Aquilion ONE Vision (TOSHIBA), SOMATOM Plus4 Volume Zoom (SIEMENS, Munich, Germany), Brilliance CT (Philips, Amsterdam, The Netherlands), and Brilliance iCT (Philips). The imaging parameters for thin-section CT were as follows: tube voltage, tube current; 100 to $500 \mathrm{~mA} ; 120 \mathrm{kVp}$; scan field of view, 320 to $360 \mathrm{~mm}$; and slice thickness, $2 \mathrm{~mm}$. A real exposure control (TOSHIBA) or automatic exposure control (SIEMENS and Philips) was added to each study. All of the CT data sets were transferred to a picture archiving and communication system, which was accessible by the workstations (Volume Analyzer; SYNAPSE VINCENT, Fujifilm Corp, Tokyo, Japan) with a specialized application for the lungs. The greatest diameter of consolidation in each tumor (C) and the greatest diameter of the whole tumor including GGO $(\mathrm{T})$ were adopted with axial 2-dimensional CT 
TABLE 1. Patient characteristics

\begin{tabular}{|c|c|}
\hline Factors & $\begin{array}{c}\text { Number of patients } \\
(\mathbf{n}=\mathbf{3 2 7})\end{array}$ \\
\hline \multicolumn{2}{|l|}{ Age, y } \\
\hline Median & 69 \\
\hline Range & $29-85$ \\
\hline \multicolumn{2}{|l|}{ Sex } \\
\hline Female & $174(53.2 \%)$ \\
\hline Male & $153(46.8 \%)$ \\
\hline \multicolumn{2}{|l|}{ Smoking history } \\
\hline Mean PY & $22(0-300)$ \\
\hline Never smoker & $168(51.4 \%)$ \\
\hline Light smoker $(\mathrm{PY} \leq 30)$ & $57(17.4 \%)$ \\
\hline Heavy smoker $(\mathrm{PY}>30)$ & $102(31.2 \%)$ \\
\hline Radiologic tumor $\leq 2.0$ & $169(51.7 \%)$ \\
\hline Diameter $>2.0(\mathrm{~cm})$ & $158(48.3 \%)$ \\
\hline \multicolumn{2}{|l|}{$\mathrm{C} / \mathrm{T}$ ratio } \\
\hline$\leq 0.25$ & $52(15.9 \%)$ \\
\hline$>0.25$ & $275(84.1 \%)$ \\
\hline \multicolumn{2}{|l|}{ Pathologic tumor status } \\
\hline 1 & $217(66.4 \%)$ \\
\hline 2 & $85(26.0 \%)$ \\
\hline 3 & $18(5.5 \%)$ \\
\hline 4 & $7(2.1 \%)$ \\
\hline \multicolumn{2}{|l|}{ Pathologic nodal stage } \\
\hline 0 & $260(79.5 \%)$ \\
\hline 1 & $33(10.1 \%)$ \\
\hline 2 & $33(10.1 \%)$ \\
\hline 3 & $1(0.3 \%)$ \\
\hline \multicolumn{2}{|l|}{ Pathologic stage } \\
\hline I & $230(70.4 \%)$ \\
\hline II & $57(17.4 \%)$ \\
\hline III & $36(11.0 \%)$ \\
\hline IV & $4(1.2 \%)$ \\
\hline \multicolumn{2}{|l|}{$\mathrm{pl}^{*}$} \\
\hline Negative & $262(80.4 \%)$ \\
\hline Positive & $64(19.6 \%)$ \\
\hline \multicolumn{2}{|l|}{ ly } \\
\hline Negative & $281(85.9 \%)$ \\
\hline Positive & $46(14.1 \%)$ \\
\hline \multicolumn{2}{|l|}{$\mathrm{v}$} \\
\hline Negative & $236(72.2 \%)$ \\
\hline Positive & $91(27.8 \%)$ \\
\hline \multicolumn{2}{|l|}{ Histologic subtype } \\
\hline AAH/AIS/MIA & $36(11.0 \%)$ \\
\hline Lepidic predominant & $21(6.4 \%)$ \\
\hline Papillary predominant & $242(74.0 \%)$ \\
\hline Acinar predominant & $4(1.3 \%)$ \\
\hline Micropapillary predominant & $1(0.3 \%)$ \\
\hline Solid predominant & $19(5.8 \%)$ \\
\hline Variants & $4(1.2 \%)$ \\
\hline \multicolumn{2}{|l|}{ Surgical procedure } \\
\hline Sublobar resection & $84(25.7 \%)$ \\
\hline Lobectomy & $235(71.9 \%)$ \\
\hline
\end{tabular}

TABLE 1. Continued

\begin{tabular}{|c|c|}
\hline Factors & $\begin{array}{l}\text { Number of patients } \\
\quad(\mathbf{n}=\mathbf{3 2 7})\end{array}$ \\
\hline Bilobectomy & $4(1.2 \%)$ \\
\hline Pneumonectomy & $4(1.2 \%)$ \\
\hline \multicolumn{2}{|l|}{$E G F R^{*}$} \\
\hline Wildtype & $103(50.5 \%)$ \\
\hline Mutant & $101(49.5 \%)$ \\
\hline \multicolumn{2}{|l|}{ PD-L1 expression } \\
\hline Negative & $268(82.0 \%)$ \\
\hline Positive & $59(18.0 \%)$ \\
\hline \multicolumn{2}{|l|}{ STAS } \\
\hline Negative & $136(41.6 \%)$ \\
\hline Positive & $191(58.4 \%)$ \\
\hline $\begin{array}{l}P Y, \text { Pack-year; } C / T, \text { cons } \\
v, \text { vascular invasion; } A A \\
\text { in situ; } M I A, \text { minimally it } \\
\text { ceptor; } P D-L 1, \text { programı } \\
\text { in which data were avail }\end{array}$ & $\begin{array}{l}\text { on; ly, lymphatic invasion; } \\
\text { sia; AIS, adenocarcinoma } \\
\text { pidermal growth factor re- } \\
\text { through air spaces. *Cases }\end{array}$ \\
\hline
\end{tabular}

data at a 2-mm slice section; the consolidation/tumor $(\mathrm{C} / \mathrm{T})$ ratio was then calculated. Each CT feature was defined and evaluated based on previous reports $^{11-13}$ : vascular convergence pertained to vessels around the tumor; surrounding GGO was delineated on the basis of a clearly defined border with a normal lung parenchyma; air bronchogram was defined as air density surrounded by consolidation without prominent bronchial dilation; notch was defined as a portion of the surface of a lesion showing a shallow, wavy configuration, with the exception of the regions abutting the pleura; pleural indentation was defined as retraction of the pleura toward the tumor with a linear structure originating from the tumor and extending to the pleural surface; spiculation was defined as the presence of linear strands extending from the nodule or mass margin into the lung parenchyma without reaching the pleural surface; and cavitation was characterized by the presence of round or oval air density in the tumor with a relatively thick wall. In this study, 1 thoracic surgeon (G.T., with 12 years of experience) and 1 thoracic radiologist (T.K., with 19 years of experience) independently analyzed the CT features. The 2 assessors were blinded to the STAS status of the enrolled patients before the analyses described to follow. If the independent assessments did not agree, G.T. and T.K. had a discussion to reach a final consensus.

\section{Statistical Analyses}

Interobserver agreement was assessed by the $\kappa$ coefficient. The associations between the PD-L1 expression and patient characteristics were analyzed with the Fisher exact test, and univariable and multivariable analyses of the relationship between STAS and the CT features of vascular convergence, surrounding GGO, air bronchogram, notch, pleural indentation, spiculation, and cavitation were performed by a logistic regression analysis with backward elimination. The overall survival (OS) was defined as the time from the initial surgery until death from any cause, whereas the recurrence-free survival (RFS) was defined as the time from the initial surgery until recurrence. The survival curves were generated with the KaplanMeier method and compared with the log-rank test. The prognostic factors for the RFS and OS were assessed using a logistic regression model with a backward elimination method. All of the statistical analyses were conducted with the JMP, version 12, software program (SAS Institute, Cary, NC). $P$ values of $<.05$ were considered to indicate statistically significant differences. 


\begin{tabular}{|c|c|c|c|c|c|}
\hline \multicolumn{6}{|l|}{ Result 1} \\
\hline \multirow[b]{2}{*}{ Factors } & & \multirow[b]{2}{*}{$N$} & \multicolumn{2}{|c|}{ STAS } & \multirow[b]{2}{*}{$P$ value } \\
\hline & & & $\begin{array}{l}\text { Negative } \\
(n=136)\end{array}$ & $\begin{array}{l}\text { Positive } \\
\text { (n=191) }\end{array}$ & \\
\hline Age (years) & $\begin{array}{l}<70 \\
\geq 70\end{array}$ & $\begin{array}{l}172(52.6 \%) \\
155(47.4 \%)\end{array}$ & $\begin{array}{l}67(49.3 \%) \\
69(50.7 \%)\end{array}$ & $\begin{array}{r}105(55.0 \%) \\
86(45.0 \%)\end{array}$ & 0.31 \\
\hline Sex & $\begin{array}{l}\text { Female } \\
\text { Male }\end{array}$ & $\begin{array}{l}174(53.2 \%) \\
153(46.8 \%)\end{array}$ & $\begin{array}{l}75(55.2 \%) \\
61(44.8 \%)\end{array}$ & $\begin{array}{l}99(51.8 \%) \\
92(48.2 \%)\end{array}$ & 0.58 \\
\hline Smoking history & $\begin{array}{l}\text { Never-smoker } \\
\text { Light-smoker }(\mathrm{PY} \leq 30) \\
\text { Heavy-smoker }(\mathrm{PY}>30)\end{array}$ & $\begin{array}{r}168(51.4 \%) \\
57(17.4 \%) \\
102(31.2 \%)\end{array}$ & $\begin{array}{l}71(52.2 \%) \\
25(18.4 \%) \\
40(29.4 \%)\end{array}$ & $\begin{array}{l}97(50.8 \%) \\
95(16.7 \%) \\
62(32.5 \%)\end{array}$ & 0.82 \\
\hline $\begin{array}{l}\text { Radiological } \\
\text { tumor size }(\mathrm{cm})\end{array}$ & $\begin{array}{l}\leq 2.0 \\
>2.0\end{array}$ & $\begin{array}{l}169(51.7 \%) \\
158(48.3 \%)\end{array}$ & $\begin{array}{l}81(59.6 \%) \\
55(40.4 \%)\end{array}$ & $\begin{array}{r}88(46.1 \%) \\
103(53.9 \%)\end{array}$ & 0.02 \\
\hline $\begin{array}{l}\text { Pathological } \\
\text { tumor stage }\end{array}$ & $\begin{array}{l}1 \\
\geq 2\end{array}$ & $\begin{array}{l}217(66.4 \%) \\
110(33.6 \%)\end{array}$ & $\begin{array}{r}105(77.2 \%) \\
31(22.8 \%)\end{array}$ & $\begin{array}{r}110(57.6 \%) \\
81(42.4 \%)\end{array}$ & $<0.01$ \\
\hline $\begin{array}{l}\text { Pathological } \\
\text { nodal stage }\end{array}$ & $\begin{array}{l}1 \\
\geq 2\end{array}$ & $\begin{array}{r}260(79.5 \%) \\
67(20.5 \%)\end{array}$ & $\begin{array}{r}117(86.0 \%) \\
19(14.0 \%)\end{array}$ & $\begin{array}{r}143(74.9 \%) \\
48(25.1 \%)\end{array}$ & 0.02 \\
\hline $\begin{array}{l}\text { Pathological } \\
\text { stage }\end{array}$ & $\begin{array}{l}1 \\
\geq 11\end{array}$ & $\begin{array}{r}230(70.4 \%) \\
97(29.6 \%)\end{array}$ & $\begin{array}{r}107(78.7 \%) \\
29(21.3 \%)\end{array}$ & $\begin{array}{r}123(64.4 \%) \\
68(35.6 \%)\end{array}$ & $<0.01$ \\
\hline
\end{tabular}

VIDEO 1. The importance and relevance of the current study. Video available at: https://www.jtcvs.org/article/S0022-5223(18)31513-7/fulltext.

\section{RESULTS}

\section{Clinicopathologic Characteristics of the Patients and Their Associations With STAS}

Table 1 shows the characteristics of the patients included in this translational study. The number of tumors with a radiologic tumor diameter $>2.0 \mathrm{~cm}$ was $158(48.3 \%)$, and the frequencies of patients with a $\mathrm{C} / \mathrm{T}$ ratio of $>0.25$ were 275 (84.1\%). Eighty-four (25.7\%), $235(71.9 \%), 4$ $(1.2 \%)$, and $4(1.2 \%)$ patients underwent sublobar resection, lobectomy, bilobectomy, and pneumonectomy, respectively. Among 204 patients whose EGFR mutation status was available, $101(49.5 \%)$ harbored sensitive EGFR mutations. PD-L1 expression was observed in 59 patients $(18.0 \%)$. STAS was identified in 191 patients $(58.4 \%)$, whereas the remaining 136 patients $(41.6 \%)$ were negative for STAS.

The Fisher exact test demonstrated that STAS was significantly associated with radiologically and pathologically invasive features and was less frequently observed in patients who underwent sublobar resection, as shown in Table E1 (Video 1). Patients with STAS-positive adenocarcinoma exhibited a significantly shorter RFS and OS than those without $(P<.01$ and $P<.01$, respectively; Figure 1 , $A$ and $B$, and Video 1). In multivariable analyses, STAS as well as age, sex, pathologic stage, and lymphovascular invasion were independent predictors for the RFS and OS (Tables E2 and E3). In addition, STAS-positive adenocarcinomas treated with limited resection also exhibited a significantly shorter RFS and OS than those without $(P<.01$ and $P=.04$, respectively; Figure E1, $A$ and $B$ ). Patients with STAS-positive adenocarcinoma who underwent lobectomy, bilobectomy, or pneumonectomy exhibited worse RFS and OS than those without $(P<.01$ and $P=.03$, respectively; Figure E1, $C$ and $D$ ).

\section{Relationship Between STAS and CT Features}

Among 327 patients, vascular convergence, surrounding GGO, air bronchogram, notch, pleural indentation, spiculation, and cavitation were observed in $212(64.8 \%), 157$ (48.0\%), 254 (77.7\%), 111 (33.9\%), $253(77.4 \%), 139$ $(42.5 \%)$, and $53(16.2 \%)$, respectively (Table 2 and Video 1). For all features, the concordance between observers was good, with a $\kappa$ coefficient of 0.68 . In the analyses focusing on GGO and notch, the $\kappa$ coefficient was as high as 0.76 . A univariable analysis demonstrated that STAS-positive adenocarcinomas were significantly associated with a radiologic tumor diameter larger than $2.0 \mathrm{~cm}$ (odds ratio [OR], 1.72; 95\% confidence interval [CI], $1.11-2.70 ; P=.02)$, the presence of vascular convergence (OR, 2.73; 95\% CI, 1.72-4.38; $P<.01$ ), notch (OR, 2.60; 95\% CI, 1.60-4.32; $P<.01$ ), pleural indentation (OR, 1.79; 95\% CI, 1.06-3.03; $P=.03$ ), spiculation (OR, 2.44; 95\% CI, 1.54-3.91; $P<.01)$, and the absence of GGO (OR, 0.31; 95\% CI, 0.19-0.49; $P<.01$ ) compared with STAS-negative ones. In a multivariable analysis, the presence of notch (OR, 1.93; 95\% CI, 1.15-3.29; $P=.01$ ) and the absence of GGO (OR, 0.37; 95\% CI, 0.23-0.59; $P<.01)$ were shown to be significantly associated with the STAS phenomenon. As shown in Table 3, STAS was more frequently observed in adenocarcinomas with a greater $\mathrm{C} / \mathrm{T}$ ratio than in those with a lower ratio.
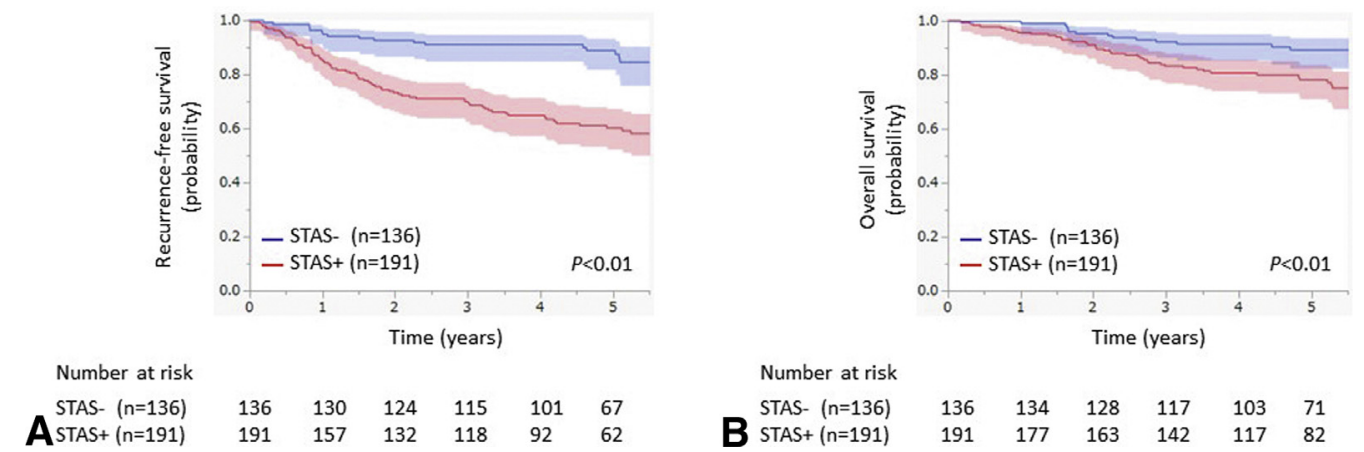

FIGURE 1. Kaplan-Meier curves according to the STAS. The (A) recurrence-free and (B) overall survivals were significantly worse in patients with STAS than in those without STAS $(P<.01$ and $P<.01$, respectively). STAS, Spread through air spaces. 
TABLE 2. Univariable and multivariable analyses for the relationship between STAS and CT features

\begin{tabular}{|c|c|c|c|c|c|c|c|}
\hline \multirow[b]{2}{*}{ CT features } & \multirow[b]{2}{*}{$\mathbf{N}$} & \multicolumn{2}{|c|}{ STAS } & \multicolumn{2}{|c|}{ Univariate analysis } & \multicolumn{2}{|c|}{ Multivariate analysis } \\
\hline & & Negative $(n=136)$ & Positive $(n=191)$ & OR $(95 \%$ CI) & $P$ value & OR $(95 \%$ CI) & $P$ value \\
\hline Radiologic tumor $\leq 2.0$ & 169 & $81(59.6 \%)$ & $88(46.1 \%)$ & 1.00 & & & \\
\hline Diameter $>2.0(\mathrm{~cm})$ & 158 & $55(40.4 \%)$ & $103(53.9 \%)$ & $1.72(1.11-2.70)$ & .02 & & \\
\hline \multicolumn{8}{|l|}{ Vascular convergence } \\
\hline- & 115 & $66(48.5 \%)$ & $49(25.7 \%)$ & 1.00 & & & \\
\hline+ & 212 & $70(51.5 \%)$ & $142(74.3 \%)$ & $2.73(1.72-4.38)$ & $<.01$ & & \\
\hline \multicolumn{8}{|l|}{ Surrounding GGO } \\
\hline - & 170 & $48(35.3 \%)$ & $122(63.9 \%)$ & 1.00 & & 1.00 & \\
\hline+ & 157 & $88(64.7 \%)$ & $69(36.1 \%)$ & $0.31(0.19-0.49)$ & $<.01$ & $0.37(0.23-0.59)$ & $<.01$ \\
\hline \multicolumn{8}{|l|}{ Air bronchogram } \\
\hline- & 73 & $27(19.9 \%)$ & $46(24.1 \%)$ & 1.00 & & & \\
\hline+ & 254 & $109(80.1 \%)$ & $145(75.9 \%)$ & $0.78(0.45-1.33)$ & .36 & & \\
\hline \multicolumn{8}{|l|}{ Notch } \\
\hline - & 216 & $106(77.9 \%)$ & $110(57.6 \%)$ & 1.00 & & 1.00 & \\
\hline+ & 111 & $30(22.1 \%)$ & $81(42.4 \%)$ & $2.60(1.60-4.32)$ & $<.01$ & $1.93(1.15-3.29)$ & .01 \\
\hline \multicolumn{8}{|l|}{ Pleural indentation } \\
\hline - & 74 & $39(28.7 \%)$ & $35(18.3 \%)$ & 1.00 & & & \\
\hline+ & 253 & $97(71.3 \%)$ & $156(81.7 \%)$ & $1.79(1.06-3.03)$ & .03 & & \\
\hline \multicolumn{8}{|l|}{ Spiculation } \\
\hline- & 188 & $95(69.8 \%)$ & $93(48.7 \%)$ & 1.00 & & & \\
\hline+ & 139 & $41(30.2 \%)$ & $98(51.3 \%)$ & $2.44(1.54-3.91)$ & $<.01$ & & \\
\hline \multicolumn{8}{|l|}{ Cavitation } \\
\hline- & 274 & $117(86.0 \%)$ & $157(82.2 \%)$ & 1.00 & & & \\
\hline+ & 53 & $19(14.0 \%)$ & $34(17.8 \%)$ & $1.33(0.73-2.49)$ & .35 & & \\
\hline
\end{tabular}

$C T$, Computed tomography; STAS, spread through air spaces; $O R$, odds ratio; $C I$, confidence interval; $G G O$, ground-glass opacity.

\section{OR for STAS Based on the Presence or Absence of GGO and Notch}

Next, we analyzed the ORs for STAS based on the presence or absence of GGO and notch. In comparison with GGO+/notch - adenocarcinomas, the OR for STAS in GGO + /notch + and GGO-/notch- adenocarcinomas was $2.91(95 \%$ CI, 1.74-4.93; $P<.01)$, whereas the OR for STAS in GGO-/notch+ was 5.01 (95\% CI, 2.73-9.52; $P<.01$ ), as shown in Figure 2 (Video 1) and Table 4. In addition, as shown in Figure E2, the combination of GGO and notch could significantly stratify the RFS and OS $(P<.01$ and $P<.01$, respectively).

TABLE 3. Relationships between the C/T ratio and STAS

\begin{tabular}{llrr}
\hline & \multicolumn{2}{c}{ STAS } & \\
\cline { 2 - 3 } C/T ratio & $\begin{array}{c}\text { Negative } \\
(\mathbf{n}=\mathbf{1 3 6})\end{array}$ & $\begin{array}{c}\text { Positive } \\
(\mathbf{n}=\mathbf{1 9 1})\end{array}$ & $\boldsymbol{P}$ value \\
\hline 0 (pure GGO) & $25(18.4 \%)$ & $10(5.3 \%)$ & $<.001$ \\
$0.1-0.25$ & $11(8.1 \%)$ & $6(3.1 \%)$ & \\
$0.26-0.5$ & $22(16.2 \%)$ & $18(9.4 \%)$ & \\
$\geq 0.51$ & $78(57.3 \%)$ & $157(82.2 \%)$ & \\
\hline
\end{tabular}

C/T, Consolidation/tumor; STAS, spread through air spaces; $G G O$, ground-glass opacity.

\section{DISCUSSION}

CT findings before the surgical resection for lung nodules can provide important information on whether they are actually neoplastic lesions, as CT characteristics, such as vascular convergence, GGO, air bronchogram, notch, pleural indentation, spiculation, and cavity, have been used to differentiate malignant lesions from nonmalignant ones. ${ }^{14}$ Specifically, GGO and solid components on CT imaging are extremely important for defining radiologic invasiveness and predicting pathologic invasive lung adenocarcinomas. A prospective study conducted by the Japan Clinical Oncology Group revealed that small nodules $\leq 2.0 \mathrm{~cm}$ in diameter with $\leq 25 \%$ solid part detected by thin-section CT can be defined as radiologic noninvasive lung adenocarcinoma, as such nodules correspond to pathologically noninvasive adenocarcinomas with very high sensitivity. ${ }^{15}$ Determining the proportion of GGO and solid parts before surgery is important for deciding on the most appropriate surgical procedures, such as lobectomy or limited resection. ${ }^{15}$ In fact, several prospective studies have been conducted to investigate the significance of limited resection for patients with small lung adenocarcinomas with some solid part, ${ }^{16,17}$ and in a nonrandomized confirmatory phase III study that assessed sublobar surgical resection for peripheral GGO dominant lung 


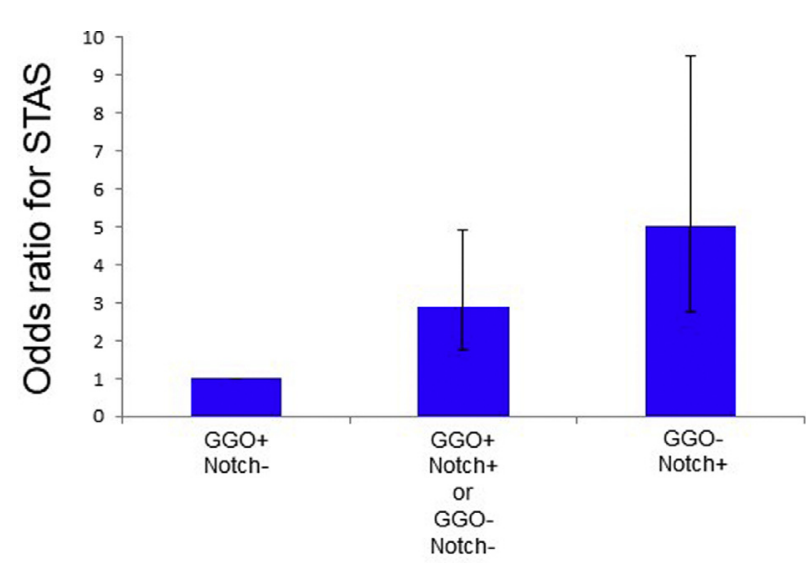

FIGURE 2. When the presence or absence of GGO was defined as 0 or 1 and the presence or absence of notch was defined as 1 or 0 , the odds ratio of scores 1 and 2 against 0 were $2.91(P<.01)$ and $5.01(P<.01)$, respectively. $S T A S$, Spread through air spaces; $G G O$, ground-glass opacity.

cancer (Japan Clinical Oncology Group 0804/ WJOG4507L), sublobar resection-mainly wedge resection-was shown to offer sufficient local control and an RFS for lung cancer with a maximum tumor diameter $\leq 2.0 \mathrm{~cm}$ and with a solid tumor ratio $\leq 0.25$ on thinsection $\mathrm{CT}^{18}{ }^{18}$ Thus, CT findings are useful for defining the radiologic (and ultimately, pathologic) invasiveness and selecting the optimum surgical method.

With regard to the STAS phenomenon, although Shiono and Yanagawa ${ }^{4}$ demonstrated that solid nodules on CT were significantly related to STAS, no reports have been conducted to investigate the associations between STAS and the detailed CT findings other than GGO. The current study was therefore the first to conduct such an investigation. We showed that the presence of notch (OR, 1.93; 95\% CI, 1.15-3.29; $P=.01)$ and the absence of GGO (OR, 0.37; 95\% CI, 0.23-0.59; $P<.01$ ) were significantly associated with the STAS phenomenon. Furthermore, GGO-negative and notch-positive adenocarcinomas exhibited an OR as high as 5.01 (95\% CI, 2.73-9.52; $P<.01)$ compared with GGO-positive and notch-negative ones. Regarding the treatment of STAS-positive lung adenocarcinomas, patients with surgically resected STASpositive adenocarcinoma exhibited a significantly shorter RFS and OS than those without STAS, as shown Figure 1, $A$ and $B$. In particular, the postoperative survival in STAS- positive adenocarcinoma treated with limited resection was significantly worse than that in patients with STASnegative adenocarcinoma (Figure E1, $A$ and $B$ ), which was consistent with the results demonstrated by Kadota and colleagues. ${ }^{1}$ Thus, objective findings obtained before surgical resection are considered beneficial for predicting STAS phenomenon and determining the optimum surgical resection (limited resection or lobectomy).

Surrounding GGO can be seen in tumors, specifically adenocarcinomas, with a replacement growth pattern of alveolar lining cells. ${ }^{19}$ The predominance of GGO suggests the noninvasiveness of tumors, as the Japan Clinical Oncology Group 0201 study defined tumors with a $\mathrm{C} / \mathrm{T}$ ratio $\leq 0.25$ on thin-section CT as radiologic noninvasive lung adenocarcinoma, since such tumors correspond well to pathologically noninvasive adenocarcinomas with very high sensitivity. ${ }^{15}$ We showed that the presence of surrounding GGO was negatively related to STAS-positive adenocarcinomas, which was in line with the results obtained by Shiono and Yanagawa ${ }^{4}$; in other words, STAS was more frequently observed in lung adenocarcinomas with a solid component than those without. As shown in Table 3, among 191 adenocarcinomas with STAS, the frequencies of STAS for C/T ratios of $0,0.1$ to $0.25,0.26$ to 0.5 , and $\geq 0.51$ were $5.3 \%$, $3.1 \%, 9.4 \%$, and $82.2 \%$, respectively $(P<.01)$, suggesting that STAS-positive adenocarcinomas are likely radiologically and pathologically invasive ones. In fact, pathologically invasive adenocarcinomas were significantly associated with the STAS phenomenon (Table E1), which may partially explain the reason for the association between STAS and the solid predominance on CT.

The notch sign reflects the expansive growth of the tumor and is a CT finding that is known to predict malignancy, because such findings indicate different growth rates of various cells at the periphery of the tumor. ${ }^{20,21}$ Although the precise reason for the relationship between the presence of notch and STAS phenomenon is difficult to explain, the finding that notch was significantly associated with invasive subtypes (data not shown), which are significantly associated with STAS formation, suggesting that the association between the presence of notch and STAS is reasonable. Future investigations are warranted to confirm these findings.

There are several limitations and concerns associated with the present study. First, this is a single-institutional

TABLE 4. OR for STAS according to the score calculated from the presence of surrounding GGO and notch

\begin{tabular}{|c|c|c|c|c|c|}
\hline & \multirow[b]{2}{*}{$\mathbf{N}$} & \multicolumn{2}{|c|}{ STAS } & \multirow[b]{2}{*}{ OR $(95 \%$ CI $)$} & \multirow[b]{2}{*}{$P$ value } \\
\hline & & Negative $(n=136)$ & Positive $(\mathrm{n}=191)$ & & \\
\hline GGO+/notch- & 128 & $77(56.6 \%)$ & $51(26.7 \%)$ & 1.00 & - \\
\hline GGO $+/$ notch + or GGO-/notch- & 117 & $40(29.4 \%)$ & $77(40.3 \%)$ & $2.91(1.74-4.93)$ & $<.01$ \\
\hline GGO-/notch + & 82 & $19(14.0 \%)$ & $63(33.0 \%)$ & $5.01(2.73-9.52)$ & $<.01$ \\
\hline
\end{tabular}

STAS, Spread through air spaces; $O R$, odds ratio; $C I$, confidence interval; $G G O$, ground-glass opacity. 
retrospective study, although we did examine a relatively large group of patients with resected lung adenocarcinoma $(\mathrm{n}=327)$. However, given the retrospective nature of this study, there was the likelihood of a selection bias by the surgeon offering sublobar resection when there was no solid component and therefore contributing to the STAS phenomenon. Thus, further prospective studies, in which the selection bias is reduced to the maximum possible extent, are needed to validate the results obtained in the present study. Second, the pathologic preparation method might affect the frequency of STAS. A multicenter prospective study conducted by Blaauwgeers and colleagues ${ }^{22}$ showed that as many as $93 \%$ of loose tissue fragments could be explained by the mechanical forces associated with tissue handling, a phenomenon that was recognized as "Spread Through A Knife Space." Thus, a precise pathologic slide preparation protocol that reduces the frequency of artifacts as much as possible is needed. Third, there is some concern that STAS might be induced by artifacts during the surgical procedure and that surgical handling or stapling techniques might affect STAS formation, a phenomenon known as "Spread Through a Surgeon." ${ }^{2}$ The results obtained in this study should be validated in multicenter studies. Fourth, the results obtained in the present study are not generalizable because $50 \%$ and $68 \%$ of the enrolled patients were $E G F R$ positive and nonsmokers/light-smokers, respectively.

In conclusion, to our knowledge, this is the first report to demonstrate close relevance between CT characteristics and STAS in 327 patients with resected lung adenocarcinomas. Given that STAS may be an independent prognosticator in adenocarcinomas treated with limited resection, our data seem useful for predicting STAS phenomenon by CT imaging before surgery and determining the appropriate surgical strategy.

\section{Conflict of Interest Statement}

Authors have nothing to disclose with regard to commercial support.

We thank Brian Quinn for his critical comments on the manuscript.

\section{References}

1. Kadota K, Nitadori J, Sima CS, Ujiie H, Rizk NP, Jones DR, et al. Tumor spread through air spaces is an important pattern of invasion and impacts the frequency and location of recurrences after limited resection for small stage I lung adenocarcinomas. J Thorac Oncol. 2015;10:806-14.

2. Warth A. Spread through air spaces (STAS): a comprehensive update. Transt Lung Cancer Res. 2017;6:501-7.

3. Warth A, Muley T, Kossakowski CA, Goeppert B, Schirmacher P, Dienemann H, et al. Prognostic impact of intra-alveolar tumor spread in pulmonary adenocarcinoma. Am J Surg Pathol. 2015;39:793-801.
4. Shiono S, Yanagawa N. Spread through air spaces is a predictive factor of recurrence and a prognostic factor in stage I lung adenocarcinoma. Interact Cardiovasc Thorac Surg. 2016;23:567-72.

5. Uruga H, Fujii T, Fujimori S, Kohno T, Kishi K. semiquantitative assessment of tumor spread through air spaces (STAS) in early-stage lung adenocarcinomas. J Thorac Oncol. 2017;12:1046-51.

6. Morimoto J, Nakajima T, Suzuki H, Nagato K, Iwata T, Yoshida S, et al. Impact of free tumor clusters on prognosis after resection of pulmonary adenocarcinoma. J Thorac Cardiovasc Surg. 2016;152:64-72.e61.

7. Kadota K, Kushida Y, Katsuki N, Ishikawa R, Ibuki E, Motoyama M, et al. Tumor spread through air spaces is an independent predictor of recurrence-free survival in patients with resected lung squamous cell carcinoma. Am J Surg Pathol. 2017; 41:1077-86.

8. Lu S, Tan KS, Kadota K, Eguchi T, Bains S, Rekhtman N, et al. Spread through air spaces (STAS) is an independent predictor of recurrence and lung cancerspecific death in squamous cell carcinoma. J Thorac Oncol. 2017;12:223-34.

9. Kohno M, Okamoto T, Suda K, Shimokawa M, Kitahara H, Shimamatsu S, et al. Prognostic and therapeutic implications of aromatase expression in lung adenocarcinomas with EGFR mutations. Clin Cancer Res. 2014;20:3613-22.

10. Takada K, Okamoto T, Shoji F, Shimokawa M, Akamine T, Takamori S, et al. Clinical significance of PD-L1 protein expression in surgically resected primary lung adenocarcinoma. J Thorac Oncol. 2016;11:1879-90.

11. Toyokawa G, Takada K, Okamoto T, Shimokawa M, Kozuma Y, Matsubara T, et al. Computed tomography features of lung adenocarcinomas with programmed death ligand 1 expression. Clin Lung Cancer. 2017;18:e375-83.

12. Hasegawa M, Sakai F, Ishikawa R, Kimura F, Ishida H, Kobayashi K. CT features of epidermal growth factor receptor-mutated adenocarcinoma of the lung: comparison with nonmutated adenocarcinoma. J Thorac Oncol. 2016;11:819-26.

13. Zhou JY, Zheng J, Yu ZF, Xiao WB, Zhao J, Sun K, et al. Comparative analysis of clinicoradiologic characteristics of lung adenocarcinomas with ALK rearrangements or EGFR mutations. Eur Radiol. 2015;25:1257-66.

14. Kuriyama K, Tateishi R, Doi O, Kodama K, Tatsuta M, Matsuda M, et al. CTpathologic correlation in small peripheral lung cancers. AJR Am J Roentgenol. 1987; 149:1139-43.

15. Suzuki K, Koike T, Asakawa T, Kusumoto M, Asamura H, Nagai K, et al. A prospective radiological study of thin-section computed tomography to predict pathological noninvasiveness in peripheral clinical IA lung cancer (Japan clinical oncology group 0201). J Thorac Oncol. 2011;6:751-6.

16. Nakamura K, Saji H, Nakajima R, Okada M, Asamura H, Shibata T, et al. A phase III randomized trial of lobectomy versus limited resection for small-sized peripheral non-small cell lung cancer (JCOG0802/WJOG4607L). Jpn J Clin Oncol. 2010;40:271-4.

17. Suzuki K, Watanabe S, Mizusawa J, Moriya Y, Yoshino I, Tsuboi M, et al. Predictors of non-neoplastic lesions in lung tumours showing ground-glass opacity on thin-section computed tomography based on a multi-institutional prospective study. Interact Cardiovasc Thorac Surg. 2015;21:218-23.

18. Suzuki K, Watanabe S, Wakabayashi M, Moriya Y, Yoshino I, Tsuboi M, et al. A nonrandomized confirmatory phase III study of sublobar surgical resection for peripheral ground glass opacity dominant lung cancer defined with thoracic thin-section computed tomography (JCOG0804/WJOG4507L). J Clin Oncol. 2017;35(suppl 15):8561.

19. Kuriyama K, Seto M, Kasugai T, Higashiyama M, Kido S, Sawai Y, et al. Ground-glass opacity on thin-section CT: value in differentiating subtypes of adenocarcinoma of the lung. AJR Am J Roentgenol. 1999;173:465-9.

20. Li Y, Chen KZ, Wang J. Development and validation of a clinical prediction model to estimate the probability of malignancy in solitary pulmonary nodules in Chinese people. Clin Lung Cancer. 2011;12:313-9.

21. Zerhouni EA, Stitik FP, Siegelman SS, Naidich DP, Sagel SS, Proto AV, et al. CT of the pulmonary nodule: a cooperative study. Radiology. 1986;160:319-27.

22. Blaauwgeers H, Flieder D, Warth A, Harms A, Monkhorst K, Witte B, et al. A prospective study of loose tissue fragments in non-small cell lung cancer resection specimens: an alternative view to "spread through air spaces." Am J Surg Pathol. 2017;41:1226-30.

Key Words: spread through air spaces, computed tomography, lung adenocarcinoma, surgery 


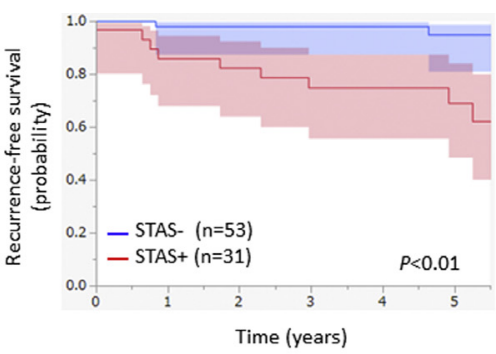

Number at risk

$\begin{array}{lllllll}\text { ATAS- }(n=53) & 53 & 52 & 51 & 50 & 41 & 26\end{array}$

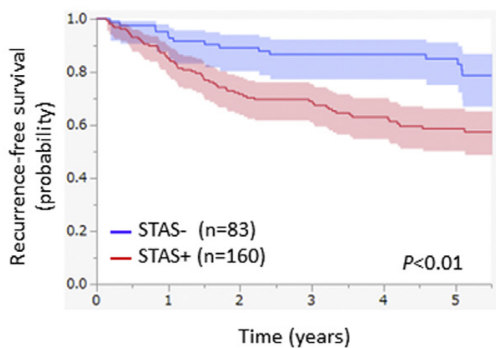

Number at risk

STAS- $(n=83)$

C ${ }_{\text {STAS }}(n=160)$

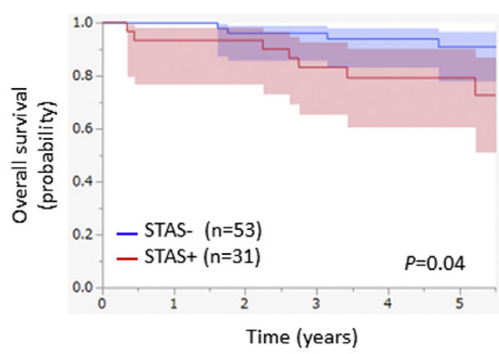

Number at risk

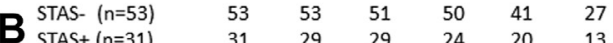

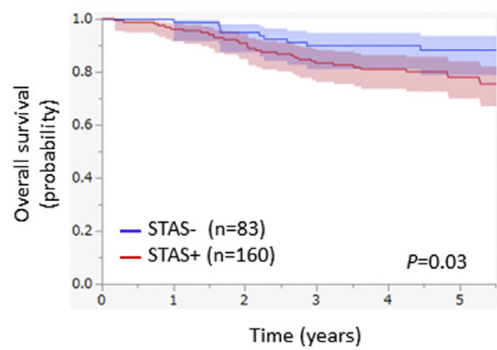

Number at risk

STAS- $(n=83)$

D STAS- $+(n=83)$

FIGURE E1. Kaplan-Meier curves for STAS-positive adenocarcinomas that underwent limited resection and lobectomy/bilobectomy/pneumonectomy. When limited to patients who underwent limited resection, (A) recurrence-free and (B) overall survivals were significantly worse in patients with STAS than in those without STAS $(P<.01$ and $P=.04$, respectively). In patients who underwent lobectomy, bilobectomy, or pneumonectomy, (C) recurrence-free and (D) overall survivals were significantly worse in patients with STAS than in those without STAS $(P<.01$ and $P=.03$, respectively). STAS, Spread through air spaces.
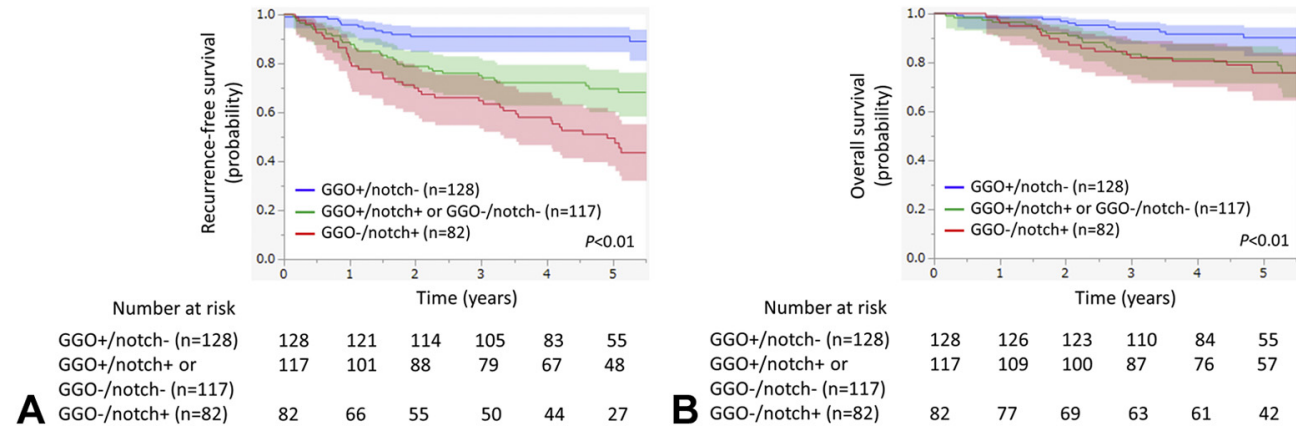

FIGURE E2. The Kaplan-Meier curves according to the presence of GGO and notch. The combination of GGO and notch findings could significantly stratify (A) recurrence-free and (B) overall survivals $(P<.01$ and $P<.01$, respectively). $G G O$, Ground-glass opacity. 
TABLE E1. The association between the STAS and the clinicopathologic factors in patients with resected adenocarcinoma

\begin{tabular}{|c|c|c|c|}
\hline Factors & $\mathbf{N}$ & STAS negative $(n=136) /$ positive $(n=191)$ & $P$ value \\
\hline \multicolumn{4}{|l|}{ Age, y } \\
\hline$<70$ & $172(52.6 \%)$ & $67(49.3 \%) / 105(55.0 \%)$ & .31 \\
\hline$\geq 70$ & $155(47.4 \%)$ & $69(50.7 \%) / 86(45.0 \%)$ & \\
\hline \multicolumn{4}{|l|}{ Sex } \\
\hline Female & $174(53.2 \%)$ & $75(55.2 \%) / 99(51.8 \%)$ & .58 \\
\hline Male & $153(46.8 \%)$ & $61(44.8 \%) / 92(48.2 \%)$ & \\
\hline \multicolumn{4}{|l|}{ Smoking history } \\
\hline Never-smoker & $168(51.4 \%)$ & $71(52.2 \%) / 97(50.8 \%)$ & .82 \\
\hline Light smoker $(\mathrm{PY} \leq 30)$ & $57(17.4 \%)$ & $25(18.4 \%) / 95(16.7 \%)$ & \\
\hline Heavy smoker $(\mathrm{PY}>30)$ & $102(31.2 \%)$ & $40(29.4 \%) / 62(32.5 \%)$ & \\
\hline Radiologic tumor $\leq 2.0$ & $169(51.7 \%)$ & $81(59.6 \%) / 88(46.1 \%)$ & .02 \\
\hline Diameter $>2.0(\mathrm{~cm})$ & $158(48.3 \%)$ & $55(40.4 \%) / 103(53.9 \%)$ & \\
\hline \multicolumn{4}{|l|}{$\mathrm{C} / \mathrm{T}$ ratio } \\
\hline$\leq 0.25$ & $52(15.9 \%)$ & $36(26.5 \%) / 16(8.4 \%)$ & $<.01$ \\
\hline$>0.25$ & $275(84.1 \%)$ & $100(73.5 \%) / 175(91.6 \%)$ & \\
\hline \multicolumn{4}{|l|}{ Pathologic tumor stage } \\
\hline 1 & $217(66.4 \%)$ & $105(77.2 \%) / 110(57.6 \%)$ & $<.01$ \\
\hline$\geq 2$ & $110(33.6 \%)$ & $31(22.8 \%) / 81(42.4 \%)$ & \\
\hline \multicolumn{4}{|l|}{ Pathologic nodal stage } \\
\hline 0 & $260(79.5 \%)$ & $117(86.0 \%) / 143(74.9 \%)$ & .02 \\
\hline$\geq 1$ & $67(20.5 \%)$ & $19(14.0 \%) / 48(25.1 \%)$ & \\
\hline \multicolumn{4}{|l|}{ Pathologic stage } \\
\hline I & $230(70.4 \%)$ & $107(78.7 \%) / 123(64.4 \%)$ & $<.01$ \\
\hline$\geq \mathrm{II}$ & $97(29.6 \%)$ & $29(21.3 \%) / 68(35.6 \%)$ & \\
\hline \multicolumn{4}{|l|}{$\mathrm{pl}^{*}$} \\
\hline Negative & $262(80.4 \%)$ & $116(85.3 \%) / 146(76.8 \%)$ & .07 \\
\hline Positive & $64(19.6 \%)$ & $20(14.7 \%) / 44(23.2 \%)$ & \\
\hline \multicolumn{4}{|l|}{ ly } \\
\hline Negative & $281(85.9 \%)$ & $125(91.9 \%) / 156(81.7 \%)$ & $<.01$ \\
\hline Positive & $46(14.1 \%)$ & $11(8.1 \%) / 35(18.3 \%)$ & \\
\hline \multicolumn{4}{|l|}{$\mathrm{v}$} \\
\hline Negative & $236(72.2 \%)$ & $106(77.9 \%) / 130(68.1 \%)$ & .06 \\
\hline Positive & $91(27.8 \%)$ & $30(22.1 \%) / 61(31.9 \%)$ & \\
\hline \multicolumn{4}{|l|}{ Histologic subtype } \\
\hline AAH/AIS/MIA & $36(11.0 \%)$ & $25(18.4 \%) / 11(5.8 \%)$ & $<.01$ \\
\hline Others & $291(89.0 \%)$ & $111(81.6 \%) / 180(94.2 \%)$ & \\
\hline \multicolumn{4}{|l|}{ Surgical procedure } \\
\hline Sublobar resection & $84(25.7 \%)$ & $54(39.7 \%) / 32(16.8 \%)$ & $<.01$ \\
\hline Lobectomy or greater & $243(74.3 \%)$ & $82(60.3 \%) / 159(83.2 \%)$ & \\
\hline \multicolumn{4}{|l|}{$E G F R^{*}$} \\
\hline Wildtype & $103(50.5 \%)$ & $39(44.3 \%) / 64(55.2 \%)$ & .16 \\
\hline Mutant & $101(49.5 \%)$ & $49(55.7 \%) / 52(44.8 \%)$ & \\
\hline \multicolumn{4}{|l|}{ PD-L1 expression } \\
\hline Negative & $268(82.0 \%)$ & $114(83.8 \%) / 154(80.6 \%)$ & .56 \\
\hline Positive & $59(18.0 \%)$ & $22(16.2 \%) / 37(19.4 \%)$ & \\
\hline
\end{tabular}

$S T A S$, Spread through air spaces; $P Y$, pack-year; $C / T$, consolidation/tumor; $p l$, pleural invasion; $l y$, lymphatic invasion; $v$, vascular invasion; $A A H$, atypical adenomatous hyperplasia; $A I S$, adenocarcinoma in situ; $M I A$, minimally invasive adenocarcinoma; $E G F R$, epidermal growth factor receptor; PD-L1, programmed death-ligand 1 . *Cases in which data were available. 
TABLE E2. Univariate and multivariate analyses of the relationship between the recurrence-free survival and the clinicopathologic factors

\begin{tabular}{|c|c|c|c|c|}
\hline \multirow[b]{2}{*}{ Factors } & \multicolumn{2}{|c|}{ Univariate analysis } & \multicolumn{2}{|c|}{ Multivariate analysis } \\
\hline & HR $(95 \%$ CI $)$ & $P$ value & HR $(95 \%$ CI $)$ & $P$ value \\
\hline \multicolumn{5}{|l|}{ Age, $y$} \\
\hline$<70$ & 1.00 & & 1.00 & \\
\hline$\geq 70$ & $1.26(0.84-1.89)$ & .27 & $1.73(1.14-2.62)$ & .01 \\
\hline \multicolumn{5}{|l|}{ Sex } \\
\hline Female & 1.00 & & 1.00 & \\
\hline Male & $1.85(1.23-2.81)$ & $<.01$ & $1.57(1.03-2.40)$ & .04 \\
\hline \multicolumn{5}{|l|}{ Smoking history } \\
\hline Never smoker & 1.00 & & & \\
\hline Smoker & $1.53(1.10-2.31)$ & .04 & & \\
\hline \multicolumn{5}{|l|}{ Pathologic stage } \\
\hline I & 1.00 & & 1.00 & \\
\hline$\geq \mathrm{II}$ & $6.12(4.02-9.47)$ & $<.01$ & $4.11(2.64-6.49)$ & $<.01$ \\
\hline \multicolumn{5}{|l|}{$\mathrm{pl}^{*}$} \\
\hline Negative & 1.00 & & & \\
\hline Positive & $3.77(2.46-5.70)$ & $<.01$ & & \\
\hline \multicolumn{5}{|l|}{ ly } \\
\hline Negative & 1.00 & & 1.00 & \\
\hline Positive & $5.62(3.63-8.55)$ & $<.01$ & $3.52(2.21-5.53)$ & $<.01$ \\
\hline \multicolumn{5}{|l|}{$\mathrm{v}$} \\
\hline Negative & 1.00 & & & \\
\hline Positive & $3.53(2.34-5.32)$ & $<.01$ & & \\
\hline \multicolumn{5}{|l|}{ Histologic subtype } \\
\hline AAH/AIS/MIA & 1.00 & & & \\
\hline Others & $14.27(3.18-251.45)$ & $<.01$ & & \\
\hline \multicolumn{5}{|l|}{ Surgical procedure } \\
\hline Sublobar & 1.00 & & & \\
\hline Lobectomy or greater & $2.93(1.63-5.82)$ & $<.01$ & & \\
\hline \multicolumn{5}{|l|}{$E G F R^{*}$} \\
\hline Wildtype & 1.00 & & & \\
\hline Mutant & $0.61(0.35-1.03)$ & .06 & & \\
\hline \multicolumn{5}{|l|}{ PD-L1 } \\
\hline Negative & 1.00 & & & \\
\hline Positive & $1.56(0.96-2.44)$ & .07 & & \\
\hline \multicolumn{5}{|l|}{ STAS } \\
\hline Negative & 1.00 & & 1.00 & \\
\hline Positive & $3.43(2.12-5.85)$ & $<.01$ & $2.77(1.70-4.75)$ & $<.01$ \\
\hline
\end{tabular}


TABLE E3. Univariate and multivariate analyses of the relationship between the overall survival and the clinicopathological factors

\begin{tabular}{|c|c|c|c|c|}
\hline \multirow[b]{2}{*}{ Factors } & \multicolumn{2}{|c|}{ Univariate analysis } & \multicolumn{2}{|c|}{ Multivariate analysis } \\
\hline & HR $(95 \%$ CI) & $P$ value & HR $(95 \%$ CI $)$ & $P$ value \\
\hline \multicolumn{5}{|l|}{ Age, y } \\
\hline$<70$ & 1.00 & & 1.00 & \\
\hline$\geq 70$ & $2.60(1.54-4.54)$ & $<.01$ & $4.48(2.55-8.13)$ & $<.01$ \\
\hline \multicolumn{5}{|l|}{ Sex } \\
\hline Female & 1.00 & & 1.00 & \\
\hline Male & $2.38(1.41-4.11)$ & $<.01$ & $2.42(1.42-4.22)$ & $<.01$ \\
\hline \multicolumn{5}{|l|}{ Smoking history } \\
\hline Never smoker & 1.00 & & & \\
\hline Smoker & $1.71(1.02-2.89)$ & .04 & & \\
\hline \multicolumn{5}{|l|}{ Pathologic stage } \\
\hline I & 1.00 & & 1.00 & \\
\hline$\geq \mathrm{II}$ & $4.72(2.82-8.06)$ & $<.01$ & $2.78(1.53-5.12)$ & $<.01$ \\
\hline \multicolumn{5}{|l|}{$\mathrm{pl}^{*}$} \\
\hline Negative & 1.00 & & & \\
\hline Positive & $3.58(2.12-5.96)$ & $<.01$ & & \\
\hline \multicolumn{5}{|l|}{ ly } \\
\hline Negative & 1.00 & & 1.00 & \\
\hline Positive & $4.15(2.39-6.99)$ & $<.01$ & $2.59(1.43-4.61)$ & $<.01$ \\
\hline \multicolumn{5}{|l|}{$\mathrm{v}$} \\
\hline Negative & 1.00 & & 1.00 & \\
\hline Positive & $3.62(2.18-6.06)$ & $<.01$ & $1.97(1.09-3.59)$ & .03 \\
\hline \multicolumn{5}{|l|}{ Histologic subtype } \\
\hline AAH/AIS/MIA & 1.00 & & & \\
\hline Others & $8.54(1.88-150.93)$ & $<.01$ & & \\
\hline \multicolumn{5}{|l|}{ Surgical procedure } \\
\hline Sublobar & 1.00 & & & \\
\hline Lobectomy or greater & $1.65(0.89-3.34)$ & .12 & & \\
\hline \multicolumn{5}{|l|}{$E G F R^{*}$} \\
\hline Wildtype & 1.00 & & & \\
\hline Mutant & $0.47(0.22-0.95)$ & .03 & & \\
\hline \multicolumn{5}{|l|}{ PD-L1 } \\
\hline Negative & 1.00 & & & \\
\hline Positive & $1.70(0.94-2.92)$ & .08 & & \\
\hline \multicolumn{5}{|l|}{ STAS } \\
\hline Negative & 1.00 & & 1.00 & \\
\hline Positive & $2.41(1.38-4.47)$ & $<.01$ & $2.11(1.18-3.96)$ & .01 \\
\hline
\end{tabular}

$H R$, Hazard ratio; $C I$, confidence interval; $p l$, pleural invasion; $l y$, lymphatic invasion; $v$, vascular invasion; $A A H$, atypical adenomatous hyperplasia; $A I S$, adenocarcinoma in situ; $M I A$, minimally invasive adenocarcinoma; EGFR, epidermal growth factor receptor; PD-L1, programmed death-ligand $1 ;$ STAS, spread through air spaces. *Cases in which data were available. 